\title{
LIFE QUALITY OF INJURED DEFENCE FORCES VETERANS WHO PLAY SITTING VOLLEYBALL
}

\author{
Raini Stamm ${ }^{1}$, Laura Rogenbaum ${ }^{2}$, Meelis Stamm ${ }^{3}$ \\ ${ }^{1}$ Institute of Health Sciences and Sports, Tallinn University, Tallinn, Estonia \\ ${ }^{2}$ Estonian Volleyball Federation \\ ${ }^{3}$ Headquarters of Estonian Defence Forces, Tallinn, Estonia
}

\begin{abstract}
The purpose of the study was to analyse the life quality and changes in it throughout three different periods in Estonian injured war veterans' life (before the injury, after the injury and after starting to play sitting volleyball). The main questions the veterans were asked concerned the positive and negative aspects of sitting volleyball, the effect of sitting volleyball on their health and social life, the motivating factors for participating in athletic activities, and whether the rehabilitation process followed the national strategies. The interviewees were nine male injured Estonian Defence Forces war veterans who play sitting volleyball. Veterans' subjective assessments of life quality were examined with paired samples t-test in SPSS program to find the mean values of veterans' assessments. The results of the study reveal that it is very important for the disabled to socialise through team sports. The support of family and friends, also setting smaller result-oriented goals help to keep discipline, contribute to a feeling of belonging and self-esteem, and all these help the veterans to get back on track after life-changing injuries. In conclusion, the analysis of the life quality of nine Estonian war veterans revealed that the decrease of mean values after the injury was significant $[t=6.825(\mathrm{p}<0.001)]$, and the increase after they started playing sitting volleyball was also significant $[\mathrm{t}(8)=-8.083(\mathrm{p}<0.001)]$.

According to the study, Estonian war veterans found many positive aspects in playing sitting volleyball, which affected their quality of life. The main aspects were team spirit, feeling of usefulness, improvement of balance, physique and health, setting goals and achieving results in sports, sharing their problems with others involved and that other people respected their ability to play instead of looking at their injuries. The most important aspect was better social life. The factors that motivated veterans to continue their rehabilitation
\end{abstract}


were support by family and friends, self-growth, teammates and other injured veterans. The Estonian Defence Forces support veterans thoroughly and introduce them to different sports including sitting volleyball during their rehabilitation. By doing that, the Defence Forces fill the requirements of national strategies to help veterans return to their regular lifestyle. The current study could be helpful for veterans for making better and more informed choices in rehabilitation after the injury and faster return to their desired quality of life. The results could also help to improve the restoration of health and social life. The results are helpful for the development and popularisation of sitting volleyball in Estonia.

Keywords: sitting volleyball; injured war veterans; health; social life; rehabilitation; recreational activities

\section{INTRODUCTION}

Quality of life has been described as a multidimensional concept that does not include only clinical information but also everyone's subjective opinion of their wellbeing [5]. Several studies have shown that practising any kind of sports and recreational activities improves the life quality of people with special needs $[8,10,13]$. People with special needs who practise sports have a higher self-esteem; they are more confident and cope better in independent life. Positive impact on physical form, psychology, sociality and economic status has also been found [8].

The aim of the current study was to give an overview of the life quality of injured veterans of the Estonian Defence Forces who play sitting volleyball and changes in their life quality in three stages of life - before the injury, after the injury and after starting to play sitting volleyball.

Depending on the aim of the study, the following research tasks were set:

1. To find how playing sitting volleyball influences veterans' health and social life.

2. To find which factors motivate veterans to practise sports.

\section{MATERIAL AND METHODS}

The sample for the current study consisted of veterans of the Defence Forces of Estonia who were injured during a mission or have permanent injuries caused by participating in missions. The total number of veterans with irrecoverable 
injuries who play sitting volleyball in Estonia is nine. During the study, the author conducted interviews with all of them.

The servicemen's age ranged from 31 to 41 years; their mean age was 35.9 years. All the interviewees were men; there are no female members of the Defence Forces of Estonia who play sitting volleyball. Their mean period of work in the Defence Forces was 14.5 years; at present seven out of the nine respondents continue active service; two work for other employers.

The interviews with the subjects were conducted and the data interpreted by Laura Rogenbaum who is also an active sitting volleyball player and is responsible for the development of sitting volleyball in the Estonian Volleyball Union.

\section{RESULTS}

The subjects of the study were nine veterans of the Defence Forces of Estonia. Eight of them had been to more than one foreign mission; only for one of them, the first mission remained the last because of the injury. A third of the men had been to missions again after recovery from injuries and would like to participate in foreign missions in the future, although, because of injuries, their opportunities for work are limited, and, thus, it is more difficult for them to get elected. The wish to go was substantiated, for example, by the environment differing from the usual, peace and quiet, leaving behind the routine of life, adrenaline, unfinished tasks, and a feeling that companions had been let down. One of the respondents had been injured for the second time, but then his injuries were less severe, and he still wants to return to the combat region.

Most injuries were caused by stepping on self-made explosive devices or falling because of their explosions; the injuries of only one serviceman were caused by a rare bacterium in the organism that paralysed the nervous system. Four of the interviewed servicemen had one or two legs amputated; one has impaired function of arms because of an explosion and also a bullet wound, one has muscle contraction impairment; one had nerves cut through during operations after the accident, and, therefore, the function of muscles has deteriorated, and one man has continuous muscle tremors and an accompanying speech defect caused by brain damage. All the wounded had different lesser injuries over the whole body, but for our study, those that have influenced the men's everyday life and activity on the sitting volleyball court until the present were the most essential.

The initial life of all the interviewees after the accident was similar. After first aid and the first operations in the battle zone, the men were taken, either 
directly or through the Estonian medical system, to a hospital in Britain and, from there, to rehabilitation therapy. All of them began the rehabilitation process in the wheelchair, and it was long and complicated. It lasted mostly from one to four years, but, to a smaller extent, it has continued for the majority after ten years until the present. Rehabilitation included occupational therapy, strength and balance training, swimming. All of this required frequent travelling between Estonia and Britain and being away from home and families for months. Many of them had to learn to walk again, either on their own legs or on one or two protheses. Serviceman 1 mentions that, when he was injured, treatment of the amputated and making of protheses in Estonia was not at the same level as elsewhere in the world. When the man went to Britain with his first prothesis with which it was impossible to walk, his "wooden leg" was laughed at, as such a thing had not been seen in Britain before. After getting a new and better prosthetic leg, he could learn to walk again. The interviewee adds that nowadays this area is at a top level in Estonia, and there are no differences with other countries anymore. This was also confirmed by serviceman 2 who has worked for several years as a prothesis maker at the only post-amputation rehabilitation centre in Estonia and has made comfortable protheses for himself and hundreds of patients.

When speaking about the period after the injury, most servicemen mentioned that the prevailing emotions were fear for the future, feeling of hopelessness and confusion. The confusion was caused by the simultaneous wish to return to work immediately so as not to let the companions down and the feeling that life had finished. Many injured men mentioned the support by the Defence Forces of Estonia as positive and helpful. The Defence Forces guarantee treatment and rehabilitation, and no one is left alone in the difficult situation. They are offered new jobs and good facilities for further recovery besides the job. All this contributes to coming out of the "hole" and progress in life.

All interviewees considered themselves very mobile and athletic people, which certainly is also related to servicemen's work tasks during missions. Before injuries, most interviewees' favourite hobbies like hunting, running, basketball, football, folk dancing, motorcycling, weight training, etc. involved a lot of motion. Serviceman 6 pointed out that his greatest fear after amputation of both legs concerned his future work. Having done physical work in the open air for all his life, it seemed most difficult for him to take up office work. By now, he has got used to it, as he can exercise by practising his hobbies. For servicemen 1, 4 and 9, it is most unpleasant that they cannot practise their favourite hobbies until the present, and most probably can never do it like they did earlier. In addition to changes in mobility and hobbies, the veterans 
considered the greatest changes caused by injuries that people were constantly "staring at them", also learning a new job, getting socialised again, changes in the tempo of life and, for some men, getting the brain used to the situation that they have no leg anymore. Serviceman 1 mentioned that a short time after the accident he fell when getting up from bed because the brain could not understand that one leg was missing. Serviceman 8 considered the greatest change the understanding of fragility of life, which made him think more carefully about all the activities and situations and their significance. After the accident, he decided to concentrate more deeply on new studies and family life.

The interviewees explained how they understood the concept of quality of life. Many considered it a very subjective indicator. In summary, quality of life consists in what people like to do, how they fill their time - work, sport, interpersonal relations, health status, family; how they personally feel and how their needs are satisfied in the areas they consider essential according to the standards set by themselves. Serviceman 2 aptly summarised the explanation: "All what I can do and how it is going, or my own opinion of how I can enjoy life. Nothing more."

The servicemen were asked to assess the quality of their life in the period before the injury on a scale from 1 (very bad) to 5 (very good). Their mean life quality indicator was 4.11 . Two respondents assessed this period in their life with grade 3 (average). "Everything seemed OK; nothing special was happening, but there was no stability in my life; things had not settled yet because of my youth and stupidity; therefore, it's a three," serviceman 7 said. Four respondents assessed their quality of life before the mission with grade 4 (good), explaining that this was a healthy young man's life - they could do sports, move around a lot, had found a pleasant job in the Defence Forces and had future career opportunities there. Serviceman 1 describes: "I was more or less satisfied with my life; it was exciting. Previously I had only lived with my parents and gone to school; this was still the beginning of my own life. Then life changed radically at once..." Three veterans assessed their earlier life quality with grade 5 (very good). Serviceman 5 adds that standards were quite different then. He would not grade this time of youth and stupidities with 5 afterwards, but then it was the peak of the life for the young man. Servicemen 2 and 3 both said that life was settled by that time, and it was pleasantly calm. "I was really satisfied with my life then. Behind this number was ... that I liked to do a lot of sports then, definitely," serviceman 2 added.

The servicemen were also asked to assess the quality of their life on the scale from 1 (very bad) to 5 (very good) in the period that followed the injury. In seven interviewees, the subjective indicator of life quality dropped by at least 
two points. Serviceman 6 who had lost both legs in the accident assessed his life quality one point lower than previously. He could find something positive in the situation, praised the top-level treatment and the support system of the Defence Forces. As negative aspects, he mentioned being away from his family for a long time and the drop in mobility. Two respondents assessed their life quality in the period after injury with grade 3 (satisfactory). To substantiate his assessment, serviceman 5 said that he managed to set himself realistic goals in several areas, and this helped him to avoid falling into depression. Two respondents, serviceman 2 who lost both legs and serviceman 7 who had brain damage assessed their life quality with the lowest grade 1 (very bad). Their main arguments were the very long rehabilitation process and getting used to the sedentary lifestyle. Five servicemen assessed the quality of their life with grade 2 (bad). The main factors were uncertainty, changes in the arrangement of life, feeling of guilt to family members as they had to do a lot for them and decreased possibilities of practising their favourite hobbies. Serviceman 2 explained, "When I got a leg in Estonia and could not even walk with it, I did not know what turn the life would take." The mean indicator of all respondents' life quality after the injury was 2 (bad), having dropped by 2.1 points compared to the period before the injury.

At greater length, we interviewed the servicemen on the topics of sitting volleyball. Most interviewees practice sitting volleyball daily now. While one of the men learned about this sport through a relative and tried it at parasports summer days, all the others reached sitting volleyball through the Defence Forces. The injured veterans of Estonian Defence Forces have participated in Invictus Games since 2016. A sitting volleyball team to represent Estonia was first sent to the Games in 2017. The news spread; more people became interested, and the veterans began to train for competitions. If, at the beginning, there was only short-time interest to prepare for a concrete competition, then the sports representative of the Defence Forces helped to find more opportunities for playing. They grew to like the workouts and the attachment to sitting volleyball increased. Later, they joined the workouts of the Estonian Sitting Volleyball Club where they practise until the present. Serviceman 3 describes, "This was related to the Invictus Games, and it was before Toronto (in 2017 - ed.); then it was said that Estonia would send its team there, and I agreed immediately." None of the men had played volleyball seriously before, although all had tried it, either at school or in summer with friends. Serviceman 5 described the situation, "I had only tapped it at someone's summer home, but I had not even played it over a real net before." Only one, serviceman 7 , had played at county championships and become a champion there. 
None of the current sitting volleyball players had played volleyball at a higher level.

In the subjects' opinion, sitting volleyball is a very technical and complicated game; it takes time to get used to the speed. The men find that the game is exciting, physically straining, although not too much, good cardio and brain training, and most of them like it because there is no load on the legs. Serviceman 3 describes, "When I went for the first times, I understood how quick and crazy this game actually is." All the interviewees considered it positive that it is a team game. Serviceman 6 compares sitting volleyball with servicemen's everyday work. Like at work, there is a support group and the rear in sitting volleyball - friends with whom you move towards the common goals side by side. "It is a great thing about the team that you can crack jokes with someone, work out together," serviceman 4 speaks about the aspects he likes. Still, the negative sides of team sport - arguments and retorts - are also mentioned. Several men acknowledge that this is a part of human relations, and, luckily, such things are quickly forgotten among men. Serviceman 1 thinks that an essential factor at workouts is that men with a similar fate can act together, and this increases motivation. In addition to technical nuances, the players consider the physical side of sitting volleyball difficult. To be tall on the court and to hit the ball well, strong body and back muscles are needed. A third of the subjects point out the significance of balance. The men whose both legs have been amputated state that if they lose balance and fall over on their back on the court, it is quite difficult to get up again, considering the speed of the game. Definitely, this is a small obstacle compared to others. Two interviewees even mention that perhaps the game would be simpler if they did not stumble on legs under the net. "Half-jokingly (giggling), I have said here during the workout that it would be simpler to play sitting volleyball if there were fewer legs," serviceman 4 comments. The men without legs, however, state that motion would still be quicker with legs, as they must both push themselves and play volleyball with hands, as others can push with legs too. Serviceman 7 feels clumsy because of muscle tremors and slow thinking while playing sitting volleyball, and, therefore, this sport is not his first preference. He goes to help his friends sometimes if he is invited and most needed.

The support by family and relatives is very essential for servicemen. Thanks to sitting volleyball, family members have taken greater interest in parasports in general and sitting volleyball in particular. Family members go to watch matches and cheer the players. They have accepted the sport as the new alternative hobby of the servicemen and encourage them to take efforts to reach their goals. Serviceman 3 noted that he and his life partner had discussed that 
healthy people who could move and do everything do not use their opportunities, but injured veterans who cannot do all of that attempt to get the maximum of what the body enables them to do.

In the men's opinion, there are enough competitions. In addition to Estonian tournaments, they play in the Baltic League of both hall and beach sitting volleyball and participate in different competitions for veterans in nearby countries. From January 2020, they also have a coach; earlier the structure of the workouts was casual - warmup, hits and play. After the coach joined them, the players hope to become more professional. The men's aims, however, are different. Four men dream of creating an Estonian sitting volleyball tournament, which presumes wider spread of the sport and several teams in different places in Estonia. The same men also have a joint goal of reaching the international arena and title competitions in the future, as all our neighbouring countries are playing there at an elite level. Four men, however, are of a different opinion. They play for their own pleasure rather; they like the game, but they have no wish to compete. Serviceman 5 explains: "I do not want to become an elite player of sitting volleyball, and I play because it's fun and cool, and it turns out well, and this is quite enough for me." Seven men out of nine complained about the scarcity of workouts but hoped to get one more workout time in the new season. One serviceman plays sitting volleyball primarily for keeping and strengthening his health, and, therefore, his goals are oriented to health, not to results.

In the servicemen's opinion, sitting volleyball has influenced their life greatly. Primarily, motion influences their general health and well-being and helps to keep weight under control. The interviewees pointed out that workouts have a disciplining effect, and continuity helps to keep up the rhythm of life. The companions and common aims help to keep up motivation for continuous action, and this does not allow thoughts of sorrow to gain ground and to grieve alone at home. Serviceman 5 says that he managed to get out of the hole with the help of good friends but adds: "Definitely, there are those whom sitting volleyball would help a lot, whom sport would join with others and help them out. It depends, at which moment someone asks you to come along."

As life-changing aspects, the men mentioned socialising, company, positive emotions and broadening of the circle of communication. This was of particular use for those who had lost many acquaintances, as they could not practice their earlier hobbies anymore, and common interests disappeared. Additionally, the interviewees pointed out that self-development and a sense of belonging helped to cope with difficulties. "When you understand that what you are doing is essential and useful for someone - this definitely helps to restore 
self-esteem, particularly when the injury has created a feeling of incapability and uselessness," serviceman 9 says. Serviceman 8 praises his companions, "The supportive words by your own kind definitely help, as they have gone through the same road and know what you're feeling." Serviceman 1 also speaks about the life-changing effect of sitting volleyball: "You can just be together with your own kind. And, naturally, you get out of home, you won't mope around and it's fun to mingle with people. This definitely is a very significant thing."

Finally, the servicemen were asked to assess the quality of their life on the scale from 1 (very bad) to 5 (very good) at the time of giving the interview when more than 10 years had passed since the injuries, and all of them had been active sitting volleyball players for years. Six respondents out of nine graded their life quality with 4 (good); three of them specified that, because of their injuries, some things will always remain that they cannot do; therefore, they will never reach 5 (very good) any more, and there will be one point for development. Two men gave grade 5 (very good), as they were satisfied with everything at present and would not even wish for better. Serviceman 2 even surpassed the scale and gave grade 6 . He emphasised that, because of the injury, he found a new job which is very satisfying, and he can see the world and fulfil his dreams. He describes, "I am very satisfied with my life. Certain things have become more complicated, but what happened to be brought me where I am now, and I am really satisfied with my life, and it has given me a lot...The only thing I'm missing is that I cannot run anymore. This is the only thing. But everyone is not like I am, not so positive. A lot depends on how you see yourself, and what your attitude to life is. Nothing depends on whether you have one leg, two legs, or no legs at all; everything depends on yourself. Simple and logical."

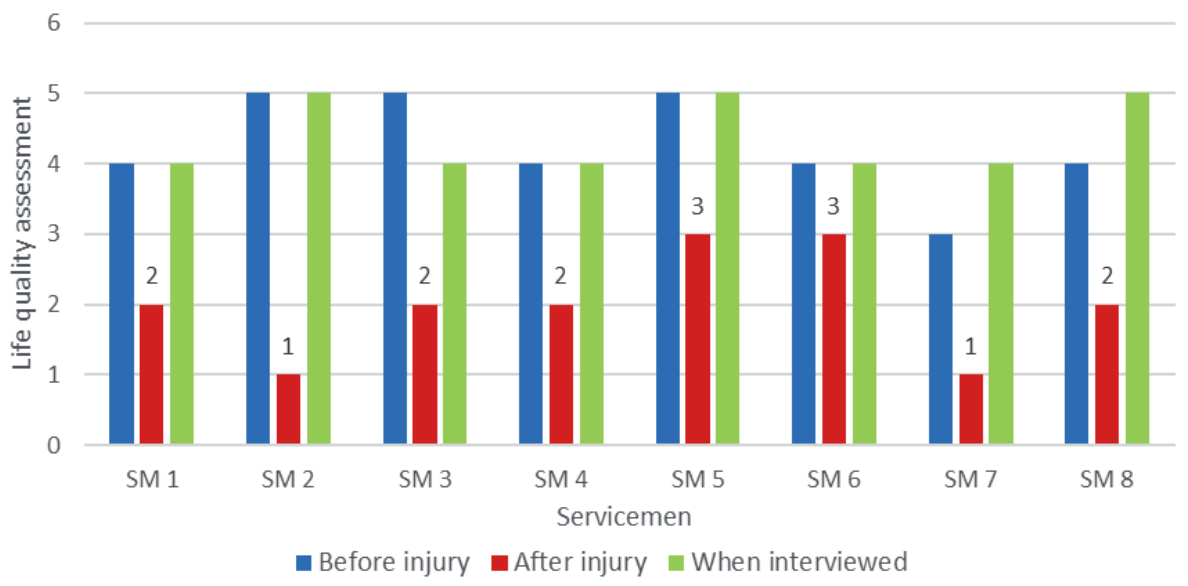

Figure 1. Veterans' assessment of life quality on a 5-point scale in different periods of life 
The bar chart shows the changes in the life quality of the interviewees in three periods in their life - before the injury, after the injury and when giving the interviews. In general, the diagram shows that the life quality of all servicemen except one has risen to the level before the injury or even higher. Using the SPSS program and the dependent samples t-test, the significance of mean differences was calculated, comparing the situation before the injury and after the injury, and after the injury and at the time of the interview. It is interesting to note that in both cases the differences were statistically significant. The difference between the servicemen's assessment of life quality before the injury ( mean value $=4.11 ; \mathrm{SD}=0.782, \mathrm{n}=9$ ) and after the injury (mean value $=2.0$, $\mathrm{SD}=0.707 ; \mathrm{n}=9$ ) was statistically significant. At the level of significance $1 \%$, $t(8)=6.825(p<0.001)$. The difference between the servicemen's assessment of life quality after the injury (mean value $=2.0 ; \mathrm{SD}=0.707, \mathrm{n}=9$ ) and the time of interviewing (mean value $=4.33, \mathrm{SD}=0.5 ; \mathrm{n}=9$ ) was also statistically significant. At the level of significance $1 \%, t(8)=-8.083(\mathrm{p}<0.001)$.

\section{DISCUSSION}

The studies conducted among disabled people by Taub et al. [14] and Charalampos et al. [2] revealed that physical health and athletic appearance (including weight loss) were the most often mentioned aspects that people with special needs considered essential when practising sports. According to Giacobbi et al. [6], athletic activities create a feeling in people that they are skilful, and this enables them to prove to others that an injury does not immediately make them disabled, and they can act equally with healthy people. One of the points in the National Health Plan is also diminishing of inequality in health, with a specific aim of increasing the choices supporting health [12]. In the Estonian servicemen's opinion, sitting volleyball has greatly influenced their life in this area during the years. First of all, volleyball influences their general physical health and well-being, helps to keep weight under control, but the veterans also state that it is pleasant that no one is "staring" at the injury but concentrates on what they are doing - the game that can played like by any healthy sports enthusiast. Just like the Welfare Development Plan says - sports contribute to equal treatment [11]. When conducting interviews with the men, the author had to state that if she did not know about their situation, she would not have understood about many that something was different - that actually the legs were missing or the whole body was covered with scars. Still, the one of the conversations revealed that, until people did not know that they were war veterans, they treated them more badly. As soon as they learned that the 
injuries were caused by action in the war zone, people seemed to change, and respect appeared.

In the interviews, veterans playing sitting volleyball praise the support system offered by the Defence Forces of Estonia, as they have different opportunities for treatment and rehabilitation. They are offered new jobs in the Defence Forces according to their health status; they can get rehabilitation and physiotherapy alongside work, and sports activities are supported in many ways. The men consider all this significant for smooth progress in their life.

The support system of the Defence Forces of Estonia is good for progress in life after injuries, but the servicemen's own mentality is also important. In their study, Christensen et al. [3] have described typical servicemen as young men in good physical form and with a special military mentality. Just because of these factors, the authors think that injured servicemen should not be compared to civilians who have experienced accidents. The men participating in the current study also stated that they had seen "everything in life", and, therefore, everyday problems did not seem difficult anymore, and their outlook had greatly changed. The veterans set themselves new, smaller goals to overcome difficulties, and took the injury as an obstacle that only the strongest meet. The men's most essential message was that one must be strong and must not surrender. Allami et al. [1] also state in their study that veterans consider namely the mental aspect their strongest side. In the case of the Estonians, this is also shown by the fact that a third of the severely injured veterans who play sitting volleyball have gone to missions again after injuries - to seek for adrenalin, as "something has been left unfinished" or because of the feeling that they have let the others down.

The job of servicemen, particularly of those participating in missions, is like a lifestyle which involves daily motion and hard physical work. Thus, all the nine war veterans interviewed had earlier actively practised different sports and hobbies which also kept themselves in shape for work. Several men said that their greatest fear after the injury was office work and immobility. The study by O'Neill and Maguire [9] found that people who had practised sports before a life-changing accident were more likely to continue after the accident as well, as this was part of their lifestyle. The significance of sport has also been pointed out by Chiampolini et al. [4] who found that movement was of greatest use for the functional abilities of parasportsmen. Nemcek [8] found that sport had a positive influence on the physique, psychology, sociality and economic status. In a special study on veterans, Jašarevic and Leutar [7] found that the positive factors were self-respect, a feeling of usefulness, positive opportunities for rehabilitation and treatment and general respect by the society. 
In retrospect, the results of the current study show that the servicemen's assessment of their life quality dropped statistically significantly considering the mean result of the nine servicemen $[t=6.825(\mathrm{p}<0.001)]$, but, by the time the interviews were conducted, had risen statistically significantly again $[t=-8,083(p<0.001)]$. The interviews revealed that, in the men's own opinion, a great share in the rise of life quality belonged namely to practising sitting volleyball. The most essential aspects that helped to improve their life quality through sitting volleyball were: team spirit, acting together with one's own kind, feeling of usefulness, improvement of balance, physique and health, not paying attention to injuries but skills on the court, sharing of worries with others, satisfaction of social needs and achievement of sports results.

\section{REFERENCES}

1. Allami M., Yavari A., Karimi A., Masoumi M., Soroush M., Faraji E. (2017). Health-related quality of life and the ability to perform activities of daily living: a cross-sectional study on 1079 war veterans with ankle-foot disorders. Review of Educational Research, 24(37), 2-8. https://doi.org/10.1186/s40779-017-0146-1

2. Charalampos S., Silva C.S., Kudlacek M. (2015). When sitting becomes sport: life stories in sitting volleyball. Euro Journal of Adapted Physical Activity, 8(1), 120-121. https://doi.org/10.5507/euj.2015.003

3. Christensen J., Ipsen T., Doherty P., Langberg H. (2016). Physical and social factors determining quality of life for veterans with lower-limb amputation(s): a systematic review. Journal of Disability and Rehabilitation, 38(24), 2345-2353. https://doi.org/10.3109/09638288.2015.1129446

4. Ciampolini V., Pinto M.G., Sousa G.R., Silva D.A.S., Galatti L.R. (2018). Do athletes with physical disabilities perceive their quality of life similarly when involved in different Paralympic Sports? Motriz. Theory and practice of physical education, 24(4), 1-6. https://doi.org/10.1590/s1980-6574201800040004

5. Fakhoury W.K.H., Priebe S. (2002). Subjective quality of life: its association with other constructs. International Review of Psychiatry, 14, 219-224. https://doi. org/10.1080/09540260220144957

6. Giacobbi P.R., Stancil M., Hardin B., Bryant L. (2008). Physical Activity and Quality of Life Experienced by Highly Active Individuals with Physical Disabilities. Human Kinetics. Adapted Physical Activity Quarterly, 25, 189-207. https://doi.org/10.1123/apaq.25.3.189

7. Jašarevic T., Leutar Z. (2010). Self-Perception of the Social Status of Disabled Ex-Soldiers (Invalids) from the Croatian Homeland War. Društvena Istraživanja / Journal for General Social Issues, 19(1), 93-116. 
8. Nemček D. (2016). Quality of life of people with disabilities from sport participation point of view. Acta Facultatis Educationis Physicae Universitatis Comenianae, 56(2), 77-92. https://doi.org/10.1515/afepuc-2016-0007

9. O'Neill S.B., Maguire S. (2004). Patient perception of the impact of sporting activity on rehabilitation in a spinal cord injuries unit. Spinal Cord, 42, 627630. https://doi.org/10.1038/sj.sc.3101651

10. Sahlin K.B., Lexell J. (2015). Impact of Organized Sports on Activity, Participation, and Quality of Life in People with Neurologic Disabilities. PM\&R, 7(10), 1081-1088. https://doi.org/10.1016/j.pmrj.2015.03.019

11. Ministry of Social Affairs (2016) Welfare Development Plan 2016-2023. Tallinn: Ministry of Social Affairs.

12. Ministry of Social Affairs (2019) National Health Plan 2020-2030. Tallinn: Ministry of Social Affairs.

13. Tasiemski T., Kennedy P., Gardner B.P., Taylor N. (2005). The association of sports and physical recreation with life satisfaction in a community sample of people with spinal cord injuries. NeuroRehabilitation, 20(4), 253-265. https:// doi.org/10.3233/NRE-2005-20403

14. Taub D.E., Blinde, E.M., Greer K.M. (1999). Stigma management through participation in sport and physical activity: Experiences of male college students with physical disabilities. Human Relations, 52, 1469-1483. https://doi. org/10.1177/001872679905201106

\section{Address for correspondence:}

Raini Stamm

Institute of Health Sciences and Sport

Tallinn University

Sireli 4, Tallinn, 10913, Estonia

E-mail: raini@tlu.ee 